\section{Autochthonous Leprosy without Armadillo Exposure, Eastern United States}

\author{
Tina Rendini, William Levis \\ Author affiliation: Bellevue Hospital Center, New York, \\ New York, USA
}

DOI: https://doi.org/10.3201/eid2311.171145

Autochthonous leprosy has been reported in New York City, where there are no wild armadillos. Recent autochthonous cases also have been reported in Georgia and Florida and blamed on armadillos, including cases with no known armadillo exposure. International migration needs to be considered as a cause of autochthonous leprosy.

I 1982, we reported that leprosy in New York City occurred exclusively among foreign-born persons (1). In 1991, Mastro et al. reported that leprosy was an epidemic phenomenon without secondary transmission (2). In 2000, however, the first autochthonous cases of leprosy in New York City were reported (3), and 2 additional autochthonous cases subsequently were reported $(4,5)$. Autochthonous leprosy has been reported in the eastern United States in Georgia (6) and central Florida (7); transmission was blamed on armadillos, even though most of these case-patients had no history of exposure to armadillos, and armadillos east of the Mississippi River rarely have leprosy (8).

Although the transmission of leprosy is poorly understood, international migration of persons with leprosy is a more likely scenario for autochthonous transmission than contact with armadillos, especially if a case-patient has no history of armadillo exposure. Ramos et al. linked an increase in autochthonous leprosy in Spain to a 5-fold increase in migration from countries where leprosy is prevalent (9). There are no wild armadillos in New York City. Autochthonous cases of leprosy reported from the eastern United States should not be assumed to be from armadillos. Physicians throughout the United States need to be aware that leprosy can occur in native-born Americans and that delayed diagnosis, which occurs frequently, can result in unacceptable deformities.

Leprosy most commonly is characterized by an infiltrative dermopathy, which dermatologists and many physicians know is an indication for skin biopsy. Many otherwise highly trained physicians are not aware of this indication for a skin biopsy, which is required to diagnose leprosy. This indication is routinely taught in dermatology clinics, but leprosy is common enough in the United States that it should be incorporated into the core curricula of medical schools. Leprosy also can be characterized by fever and arthritis simulating lupus erythematosus, rheumatoid arthritis, or antiphospholipid syndrome because autoantibodies occur in type II reaction known as erythema nodosum leprosum. Physicians should order a Fite stain on the skin biopsy specimen because Mycobacterium leprae is sensitive to the alcohol decolorizing step; if only a routine acid-fast stain (Ziehl-Neelsen) is ordered, the diagnosis is often missed (10).

Ms. Rendini is an RN training to be a nurse practitioner and works in the New York Hansen's Disease Program, Bellevue Hospital, New York, NY. She has expertise in leprosy and HIV.

Dr. Levis is a physician scientist member of the American Society of Clinical Investigation and attending physician of the New York Hansen's Disease Program, Bellevue Hospital. His research interests include leprosy, cancer, HIV, and autoimmunity.

\section{References}

1. Levis WR, Schuman JS, Friedman SM, Newfield SA. An epidemiologic evaluation of leprosy in New York City. JAMA. 1982; 247:3221-6. http://dx.doi.org/10.1001/jama.1982.03320480037023

2. Mastro TD, Redd SC, Breiman RF. Imported leprosy in the United States, 1978 through 1988: an epidemic without secondary transmission. Am J Public Health. 1992;82:1127-30. http://dx.doi.org/10.2105/AJPH.82.8.1127

3. Levis WR, Vides EA, Cabrera A. Leprosy in the eastern United States. JAMA. 2000;283:1004-5. http://dx.doi.org/10.1001/ jama.283.8.1004-a

4. Keo T, Martiniuk F, Latkowski J, Cabrera A, Rom W, Levis WR. Molecular origin of endemic leprosy in New York City. Clin Infect Dis. 2008;46:899-901. http://dx.doi.org/10.1086/528857

5. Levis WR, Paraskevas LR, Jacobson M, Spencer J, Spencer T, Martiniuk F. Endemic leprosy in New York City. Arch Dermatol. 2011;147:624-6. http://dx.doi.org/10.1001/archdermatol.2011.107

6. Lane JE, Walsh DS, Meyers WM, Klassen-Fischer MK, Kent DE, Cohen DJ. Borderline tuberculoid leprosy in a woman from the state of Georgia with armadillo exposure. J Am Acad Dermatol. 2006;55:714-6. http://dx.doi.org/10.1016/j.jaad.2006.02.070

7. Domozych R, Kim E, Hart S, Greenwald J. Increasing incidence of leprosy and transmission from armadillos in central Florida: a case series. JAAD Case Rep. 2016;2:189-92. http://dx.doi.org/10.1016/j.jdcr.2016.03.004

8. Sharma R, Singh P, Loughry WJ, Lockhart JM, Inman WB, Duthie MS, et al. Zoonotic leprosy in the southeastern United States. Emerg Infect Dis. 2015;21:2127-34. http://dx.doi.org/10.3201/eid2112.150501

9. Ramos JM, Romero D, Belinchón I. Epidemiology of leprosy in Spain: the role of the international migration. PLoS Negl Trop Dis. 2016;10:e0004321. http://dx.doi.org/10.1371/journal.pntd.0004321

10. Zhu TH, Kamangar F, Silverstein M, Fung MA. Borderline tuberculoid leprosy masquerading as granuloma annulare: a clinical and histological pitfall. Am J Dermatopathol. 2017;39:2969. http://dx.doi.org/10.1097/DAD.0000000000000698

Address for correspondence: William Levis, Bellevue Hospital CenterDermatology, 462 1st Ave, 17N7, New York, NY 10016-9198, USA; email: doctorwilliamlevis@gmail.com 